\title{
$\underline{\text { Video Testimony, Modernity, and the Claims of Melancholia }}$
}

\section{Pieter Vermeulen}

\section{For: Criticism: A Quarterly for Literature and the Arts}

The question of trauma and the issue of colonial violence and suffering, which independently have been on the critical and theoretical agenda since the 1980s, have only recently begun to be linked. Part of the blame for this prolonged stand-off falls to the field of trauma studies, which until recently failed to live up to the transcultural promise voiced by Cathy Caruth, in one of the field's foundational texts, that these days "trauma itself may provide the very link between cultures."1 Many critics have noted that this ambition was always compromised by the Eurocentric framework that the study of trauma too uncritically adopted. ${ }^{2}$ While this undeniable Eurocentrism, which is often located in the field's reliance on psychoanalytical concepts, accounts for trauma studies' blindness to the legacies of colonialism, it does not fully explain the other half of the story of this postponed encounter: postcolonial theory's reluctance to engage the trauma paradigm. Part of the problem is that trauma studies emerged in close proximity to questions of Jewish memory, and as Bryan Cheyette has shown, "there is a strand of postcolonial theory which is unable to perceive Jews as anything other than as part of a majoritarian tradition. ${ }^{3}$ Before they wrote influential accounts of traumatic memory, ${ }^{4}$ two of the leading theorists of trauma, the psychiatrist Dori Laub and the literary critic Geoffrey Hartman, were involved in the founding of the Fortunoff Video Archive for Holocaust Testimonies at Yale University in the early 1980s, which has been filming thousands of interviews with witnesses and survivors of the Holocaust. Due to the prevalent postcolonial hesitancy in recognizing Jewish experiences as minoritarian experiences, the institutional association of trauma with Jewish memory has long complicated trauma's role in promoting the transcultural circulation of memories of suffering. 
The work of Geoffrey Hartman, which almost embodies the association between trauma and Holocaust memory, may seem the worst place to track new perspectives on the transcultural dynamic of painful memories. This essay argues that Hartman's memory work, far from being focused on questions of Jewish identity, needs to be understood within the parameters of the theory of modernity that undergirds his work, and in which Wordsworth counts for much more than Moses. Even if this theory of modernity is problematic indeed, as I will not fail to underline, the aesthetic of video testimony that it informs can make a crucial contribution to contemporary discussions of the migration of Holocaust memory beyond the confines of Jewish experience. In contrast to such influential accounts as those of the sociologist Jeffrey Alexander on the 'universalization' of the Holocaust and of the literary critic Michael Rothberg on the 'multidirectional' dynamics of collective memory, Hartman's work advocates an aesthetic that makes memories of disaster radically 'unclaimable' by particular identitarian positions. His emphasis on the dangers of memory claims and his investment in the aesthetic power to pre-empt such claims underline the transcultural dynamic propelling the memory of disaster in a globalized world; at the same time, I argue that these insights into the afflictions of memory and identity are limited by a failure to appreciate that the 'claiming' of memory by subaltern groups can in certain circumstances play an enabling role in furthering a transcultural agenda. I explain this tension in Hartman's work by showing that for him, the link between memory and identity has today essentially become a formation of melancholia - a destructive posture that obsessively holds on to particular experiences of loss while anxiously pre-empting their transcultural circulation. While Hartman's account offers crucial corrections to rival theories (notably those of Alexander and Rothberg), it is compromised by his inability to observe that melancholia is not always a destructive attitude, and is sometimes even a strategic necessity in clamoring for the public acknowledgement of minoritarian experiences. 
Ever since the publication of his first book, The Unmediated Vision, in 1954, and especially since his landmark study Wordsworth's Poetry from 1964, Geoffrey Hartman's work has been undergirded by a peculiar investment in the crucial contribution that Romanticism in general, and Wordsworth in particular, have made to modernity. ${ }^{5}$ This investment is inevitably marked by a double temporality: on the one hand, there is the historical claim that Wordsworth's work has had a vital impact on modernity, while on the other, the pervasiveness of this prior claim in Hartman's work implies the further contention that it is worth remembering that contribution today. Wordsworth, in other words, organizes Hartman's work both as a historical achievement and as a critical promise. His historical role is unambiguously formulated in The Fateful Question of Culture from 1997, which contains the texts of Hartman's 1992 Wellek Library Lectures in Critical Theory. Hartman puts forward the ambitious and highly speculative thesis that "Wordsworth, writing near the beginning of the industrial revolution, achieves a precarious cultural transfer (translatio) of English rural life. ${ }^{, 6}$ His poetry neither cultivated the rural past as an available alternative nor denied its persistent appeal to a disinherited modern imagination; by giving a poetic shape to "what in English culture was previously unrealized or semi-articulate, a potententiality only," he pre-empted the phantasmagorical afterlife of the pre-industrial past as a source of antimodern resentment. The most notable long-term effect of this achievement is that English culture, which uniquely profited from Wordsworth's poetic mediation, did not have to live through the trauma of the disastrous deterioration of modernity to which Germany and France, among others, were exposed in the twentieth century. Hartman speculates that Wordsworth's poetry “saved English politics from the virulence of a nostalgic political ideal centering on rural virtue, which led to serious ravages on the continent." 
There are obvious problems with this historical claim. If it is uncontroversial enough to state that nothing comparable to the Holocaust has taken place on English soil, Hartman's Wordsworthian fantasy of an untraumatic national continuity glosses over at least two forms of violence: first, structural (rather than evental) forms of violence that are an inseparable part of English society, and second, the violence and the suffering that England has exported in the name of imperialism and colonialism. Leaving this line of critique aside for now, it is clear that Hartman's project faces the challenge of asserting the relevance of Wordsworth's historical achievement for contemporary culture. One crucial step in the wishful transfer of Wordsworth's Romanticism to the present is the assumption that the condition in which Wordsworth so successfully intervened is still - or again - the plight besetting contemporary culture. For Hartman, Wordsworth's poetry confronted a condition of "phantomization" and "derealization" brought on by the onset of commodity capitalism and industrialization's displacement of time-honored realities; his poetic mediation prevented these ghosts from persisting and fatally hardening into "an unprogressive, overidealized, image of what is lost, and thus a deeply anti-urban sentiment." ${ }^{\prime 8}$ Against a culture of abstraction, Wordsworth offered the hope of embodiment. Such abstraction, for Hartman, also afflicts contemporary culture, which, for him, is essentially a visual culture: "with the advent of television, a new kind of communal memory is created, promoting false embodiments ... each superrealism proves to be a phantom." 9 The operation of television is emblematic of contemporary culture as such, and it produces a condition that desperately calls for an update of Wordsworth's poetic power. That Hartman lays the blame for contemporary phenomena of derealization and phantomization with visual culture, rather than with, for instance, recent developments in finance capitalism or globalization, as is more routinely done, points to a characteristic blindness in his analysis. 
There is a double problem with TV. First, it is simply too powerful a "form of communication": its accumulation of ever more images has a "powerful, repetitive, everyday - and so potentially trivializing - effect," until the information and images it keeps feeding us can no longer be "assimilated" and "absorbed." 10 Second, TV not only erodes the possibility of genuine experience, as it also contributes to the "derealization of ordinary life" and to the "ghosting of reality"; it does not "respect the absence of ... absent things" but rather "conveys the illusion not of making absent things present but present things more present." 11 TV, in short, multiplies presences to the point where absence, grief, and loss no longer find a place and things can no longer be experienced, and where everything merges in a phantom space of hyperbolic visuality. It provokes a condition that calls for an update of a Wordsworthian poetics that counters the dynamic of multiplication and phantomization by insisting on the actuality of "the still unmediated, accessible, and integral - yet barely so - presence of a halfperceived and half-created mode of life." ${ }^{, 12}$ Wordsworth recognized the actuality of what resisted foregrounding, and he preserved pastoral culture as an unactualized and incomplete potentiality, which is to say as a reality that can only be reclaimed in its incompleteness, never as a full-fledged alternative to the modern condition. His poetry gave a definite shape to the ghostly persistence of the past, a persistence that, to the extent that it cannot be denied, demands some kind of embodiment.

Hartman recognizes that such an update today can no longer take the shape of poetry, as that medium has lost the authority to make a difference in a primarily visual culture. Remarkably, his work on Holocaust video testimony displays a tendency to theorize that genre as a contemporary instantiation of Wordsworth's saving mediation - as a force, that is, that because of its visual status can confront visual culture's tendency to abstraction head-on. Most of his writings on video testimony have been produced in the context of his involvement with the Fortunoff Video Archive for Holocaust Testimonies at Yale University, which has 
been recording and storing thousands of interviews with Holocaust witnesses and survivors. Hartman's extensive writings on this project have developed a particular poetics - or "optic," as he also calls it - that defines video testimony as a genre in its own right. ${ }^{13}$ For Hartman, video testimony's particular optic functions as a "counter-cinematic" genre that "use[s] television to cure television, to turn the medium against itself, limiting while exploiting its visualizing power."14

Hartman's work on video testimony is not a Fremdkörper in a career dedicated to the forms and functions of Romanticism: only taking off in the 1980s, when that career had already been well under way for three decades, it testifies to Hartman's concern to promote the pressing relevance of the particular mode of memorialization that he had unearthed in Wordsworth. ${ }^{15}$ His analysis of public memory is organized by a barely disguised analogy between the age of Wordsworth and late modernity: just as Wordsworth's poetry managed to mediate the trauma of the transition to modernity in a way that saved England from compulsively repeating that trauma in the form of an English Holocaust, so the genre of video testimony gives shape to a late modern belatedness in relation to the Holocaust in a way that will interrupt the cycle of extreme violence. This structural analogy pre-empts all attempts to immunize the Holocaust from comparisons to other memories of extreme violence; it underlines Hartman's refusal to concede the viability of any exclusive claims on traumatic memories. Video testimony is essentially an effort to re-embody the different forms of ghostliness that afflict contemporary life: the derealization spread by the media, our unchecked exposure to images of suffering and terror, the fading of the memory of catastrophe as generations of survivors disappear, and also "the phantomization or dissociation endemic to trauma." ${ }^{16}$ Hartman's most concise formulation of the rationale behind the optic of video testimony leaves no doubts about the Wordsworthian inspiration of this enterprise: 
Video is important because the voice as such, without a visible source, remains ghostly. That is, when you take away the visual, when you just hear the voice, the effect is that of disembodied sound, as if from the dead, from an absence. Voice has its own affective quality, but we feel it essential to add a face to that voice, to reduce the ghostliness, even to re-embody the voice. ${ }^{17}$

Video borrows television's visualizing powers not in order to make present things more present, but rather to give a visible and experienceable shape to testimonies that by definition deal with memories that are themselves no longer accessible to experience. Hartman's video optic, that is, is designed to enable an immediate experience of our remove from the catastrophe - a distance that is figured by the witness who is being filmed. A crucial challenge faced by this optic is developing a way to convey the "immediacy" of the interview, the fact that it is the registration of "a one-time event" happening "on the spot."18 This concern informs the Fortunoff Archive's decision not to make the interviews available on the internet, but to force potential viewers to actually travel to Yale in order to watch the video interviews there. ${ }^{19}$ The filming itself also aims to convey to the viewer the immediacy and uniqueness of the event: the interviewers only use one camera that consistently focuses on the witness, and they only rarely ask questions or prompt the interviewees. This minimalism contributes to the immediacy of the experience - i.e., to an immediate experience of our nonexperience of the memories that the witness recounts.

In the same way that Wordsworth's poetic mediations rendered the traumatic memory of the industrial interruption of pastoral unavailable to claims that would mobilize it for the cultivation of anti-modern resentment, video testimony resists our overidentification with the atrocities of the Holocaust by having its viewer experience her remove from the disaster. Video testimony denies the viewer the vicarious thrill of retraumatization, and affords an 
experience that posits her at a decisive distance from the traumatic event. It ensures that these memories cannot be claimed as the exclusive property of any constituency. Hartman's emphasis on remove - or on non-experience - is only as crucial as his emphasis on experience; the fact that video testimony affords an immediate experience of the nonexperience of the disaster allows it to serve as a point of orientation that stabilizes what Hartman analyzes as the phantom space of contemporary memory culture. Video testimony mediates our generational, geographical, and psychological distance from the experiences that are being recounted in a way that makes it possible to absorb and experience that remove. As such, it generates the position of what Hartman calls the "adoptive or intellectual witness,"20 that is, "a bystander after the event who observes it from an ambiguous position." ${ }^{21}$ The intellectual witness is, on the one hand, "detached or belated" in relation to the event, while she is also, on the other, unable not to be addressed by it and therefore called to "a more participatory state of mind." 22 Hartman's work on video testimony proposes a conception of the contemporary subject as defined by the experience of its palpable separation from disaster - a separation that can refer to a generational remove from the Holocaust, to people's nonparticipation in evident histories of suffering, or to the paradoxically derealizing effects of the omnipresence of images of extreme violence in contemporary culture. ${ }^{23}$

This double focus on experience and distance is complemented in Hartman's account by an insistence on the fact that the interviewers in the video testimonies "form a provisional community and become, for the survivor-witness, representative of a potentially larger community." ${ }^{24}$ Hartman uses Maurice Halbwachs's notion of an 'affective community' to characterize this "supportive group ready to be a 'witness to the witness'."25 The act of witnessing the witness provides the occasion for an experience that can ground a nonexclusive and non-identitarian form of community open to all who want to share this specific experience of a missed experience; it appeals "to a human commonality that does not imply 
uniformity." 26 Importantly, this provisional community cannot possibly be specifically Jewish, but is inescapably transcultural: video testimony foregrounds a necessary remove from the experiences that the witnesses recount, and this makes these memories radically 'unclaimable' - which is to say, equally (un)available to everyone who is willing to share that remove. The logic of this theorization of the genre of video testimony entails that the experience of distance can circulate and travel across cultural borders - indeed, it cannot help but transgress such borders, as the one thing it does not allow is being 'claimed' as a sacred and exclusive possession.

\section{II}

For Hartman, the genre of video testimony mediates our inevitable separation from catastrophe in a way that makes it possible to absorb and experience that remove. In order for us to appreciate the stakes of video testimony's curative operation, it is helpful to look at the potential ravages in response to which Hartman develops this claim. Video testimony is theorized as a technology that can prevent these calamities, and this explains why these dangers are in their turn connected to competing 'optics' of memory. If video testimony is a mediation that makes it possible to directly experience one's generational, geographical, and psychological distance from the Holocaust in a way that ties the viewer to these memories without retraumatizing her, a first danger in the mediation of catastrophe is a failure to let that distance be experienced. Hartman observes this danger in Spielberg's Schindler's List, which for him merely repeats television's invisible assault on experience. Recall that television has become "an intimate part of home," and as such "it becomes a treacherous servomechanism conspiring with a residual, delusory omnipotence of thoughts." ${ }^{27}$ Schindler's List feeds the same illusion: Hartman writes that "the premium placed on visuality by such a film made me deeply uneasy. To see things that sharply, and from a privileged position, is to see them with 
the eyes of those who had the power of life and death."28 The film's ambition to encompass the enormity of the events through visual means does not achieve the reality-effect that it intends, but instead leads to a film that is not realistic enough, as it fails to capture the texture of "the daily suffering in camp or ghetto" that the genre of video testimony does pay attention to. ${ }^{29}$ For this reason Hartman follows a broad critical consensus and prefers Claude Lanzmann's $\underline{\text { Shoah}}$, which does attempt to recover and communicate the details of how the Holocaust was implemented. Still, Lanzmann comes very close to the second danger involved in the mediation of catastrophe: not a failure to let the events be experienced, but a failure to emphasize the distance that separates the viewer from them. Lanzmann's approach sometimes risks a "vicarious overidentification with the victim." ${ }^{30}$ The main marker of Lanzmann's desire for a quasi-“mystical correspondence" is that, for all his commendable attention to detail, he "does not appear to be all that interested in the survivors' life or afterlife." 31

It is the third risk involved in the mediation of traumatic memory that threatens to induce the uncompromising identity-claims that the aesthetic of video testimony must ward off. This is a scenario in which the horrors of the past - or indeed the present - are fed to the viewer without any mediation that makes them digestible or even accessible to experience (Spielberg's error), nor any acknowledgement of the viewer's non-involvement in them (as almost happens in the case of $\underline{\text { Shoah}})$. The viewer is confronted with the enormity of evil and pain in a way that makes it impossible to make these horrors, or even her remove from them, a part of her identity. When it is impossible to meaningfully connect to the catastrophes from which the viewer is removed, she is abandoned to what Hartman calls "the vertigo of indecisiveness or nonidentity," which can foster "by reaction even more dangerous ... assertions." 32 Hartman is thinking here not only of "the proliferation and dailiness of secondorder images of trauma" in the media, ${ }^{33}$ but also of discourses of postmemory that describe how traumatic memory is passed on to later generations, and of aesthetic practices that rely on 
so-called secondary trauma - i.e., on "producing rather than screening the effect of trauma."34 For Hartman, the shocks of unmediated or unscreened traumas cannot be absorbed and assimilated, and merely address us on an affective level - which gives rise to feelings of powerlessness and disorientation that may generate a desire for violent overcompensation.

Hartman's work on video testimony is emphatically a second-generation discourse that is primarily interested in the question of how to manage a factual separation from experiences of extreme violence that one yet cannot fail to be addressed by. The main dangers involved are processes of secondary traumatization, in which, in Ernst van Alphen's words, a factual "lack of memories and a lack of continuity" register as a "vertigo ... in which suffering takes the place of inheritance." 35 The ghostliness that characterizes this vertigo of nonidentity may tempt people toward exclusionary and identitarian forms of embodiment, which brings on the threat of a repetition of the catastrophe that video testimony seeks to mediate into a promise of transcultural community. For Hartman, video testimony, as well as other aesthetic mediations of the Holocaust, must firmly embody the ghosts that trauma generates in a way that prevents such a vertigo of nonidentity. Such a "non-traumatizing mode of representation" should aesthetically refigure our remove as a manageable and tenable intellectual distance. ${ }^{36}$ In the context of a present-day memory culture in which it is "no longer possible not to know," yet where the accumulation of ever more "positivities" has led to "an extraordinary and melancholy record" rather than to "appreciable ethical lessons," it generates the possibility of assimilating knowledge of the past in a way that neither retraumatizes the viewer nor forces her to deny the knowledge she cannot avoid. ${ }^{37}$

Hartman's refusal of secondary traumatization as a strategy to "reconnect and reembody [a] memorial fabric that has been severed by catastrophe" ties in with his fear that a failed embodiment of the ghosts of the past will be followed by an identitarian vertigo that will in its turn generate a reactive overassertion of identity. ${ }^{38}$ In the following section, I will analyze this 
dynamic as a form of melancholia. Importantly, the analogy between Wordsworth and video testimony that underlies Hartman's work on Holocaust memory implies that there is a close affinity between present-day afflictions such as retraumatization, identitarian vertigo, and the danger of overidentification, on the one hand, and some of the psycho-social conditions that unlike Wordsworth - failed to prevent the Holocaust on the other. It suggests that the deterioration of modernity on the continent was, among many other things, an effect of a disabling sense of vertigo and belatedness. If the contemporary ubiquity of exclusionary identity formations allows us to understand the vigor of Hartman's insistence on the 'unclaiming' of trauma, lingering on this analogy a little longer puts his investment in this position into even starker relief. The idea that the Holocaust was an effect of a sense of vertigo and belatedness is not confined to Hartman's work alone: we also find it, for instance, in Philippe Lacoue-Labarthe and Jean-Luc Nancy's famous essay entitled "The Nazi Myth," which locates the scenario of a failed embodiment leading to vertigo and then to an overassertion of identity at the origin of Nazism. Lacoue-Labarthe and Nancy write that while Europe after the collapse of Christianity in the eighteenth century redefined itself through the historical imitation of classical models, Germany found itself in a particularly difficult position: "The drama of Germany was also that it suffered an imitation twice removed, and saw itself obliged to imitate the imitation of antiquity that France did not cease to export for at least two centuries. Germany, in other words, was not only missing an identity but also lacked the ownership of its means of identification." 39 Germany had no forms of its own to mediate the trauma of the collapse of Christianity, nor could the French forms that were available satisfy the desire for identity. Germany suffered what Lacoue-Labarthe and Nancy tellingly call "the vertigo of an absence of identity," and this vertigo fatefully panicked Germany into an exclusionary and identitarian myth of purity. Once these implications of the barely disguised analogy that informs Hartman's optic of video testimony are made explicit, we can 
see that it is important to underline - more emphatically than Hartman himself does - this optic's potential to offer an alternative to traditional forms of Gemeinschaft and to intimate an explicitly transcultural form of community.

\section{III}

That Hartman's theoretical work formulates such a transcultural promise does not prevent that his critical practice often fails to live up to it. That this promise is hard to substantiate in critical practice can already be glimpsed from the tension between, on the one hand, the grandiose cultural power of video testimonies that is suggested by the implicit analogy to Wordsworth - who after all managed to affect nothing less than English collective memory and the factual restrictedness of their circulation in rarified 'affective communities' on the other. Hartman's work invariably theorizes genuine experience - such as that allegedly afforded by video testimony - in opposition to mass media circulation, which is consistently and somewhat tendentiously linked to phantomization and derealization. However, even if video testimony's transcultural promise is bound to remain theoretical, it is worth locating Hartman's insistence on the 'unclaimability' of trauma in the context of other accounts of the transcultural migration of trauma. Indeed, what motivates Hartman to emphasize the need, in our contemporary media culture, to save memories and traumas from any exclusive claims upon them? Hartman is not alone in dislodging the memory of the Holocaust from exclusively Jewish claims. In an influential essay on "The Social Construction of Moral Universals," the sociologist Jeffrey Alexander has mapped the progressive 'universalization' of the Holocaust. According to Alexander, since the Eichmann trial in 1961 the Holocaust has developed into a universal touchstone that sheds light on other atrocities, and that can generate "unprecedented opportunities for ethnic, racial, and religious justice, for mutual recognition, and for global conflicts becoming regulated in a more civil way." ${ }^{40}$ Alexander's optimistic account traces 
how the memory of the Holocaust has, for almost half a century, circulated beyond the confines of particular identities and constituencies; it does so by presenting the Holocaust as a sort of superconductor that brings us directly from the singular to the universal, and that, precisely because of the ease with which it leaves behind the constraints of particular contexts, precludes a more patient comparative consideration of local mobilizations of Holocaust memory. Skipping a more detailed and historically dense consideration of the ways Holocaust memory has historically interacted with other memories of extreme violence, Alexander summarily asserts that " $[\mathrm{t}]$ he horrific trauma of the Jews became the trauma of all humankind" when the Holocaust "no longer referred to events that took place at a particular time and place. ${ }^{״ 1}$ This is very different from Hartman's account: his insistence on concrete, individual experience in the transmission of memory signals a resistance to such a notion of the Holocaust as a universally available signifier that is not burdened with the weight of particular experiences.

This criticism of Alexander has also been made by Michael Rothberg, whose book Multidirectional Memory: Remembering the Holocaust in the Age of Decolonization takes more care not to simply collapse "the transnational, the global, and the comparative into the universal. ${ }^{, 42}$ It shows how particular mobilizations of Holocaust memory always occur in, and are often made possible by, contexts that are saturated with other memories of extreme violence. In contrast to Alexander's relative disinterest in particular constellations of memory, Rothberg demonstrates how every manifestation of memory is "dense with overlapping possibilities and dangers." ${ }^{43}$ By tracing how a wide variety of particular memory claims is overdetermined by the overlap of different memories and histories, Rothberg's (roughly Benjaminian) approach allows the constellations of memorial vectors he recovers - often instances of colonial violence and of the Holocaust - to crystallize into monads that testify to the mobility and multidirectionality that characterize the transcultural circulation of memory. 
While Rothberg's many detailed case studies, each of which maps the ways a particular constellation of memory articulates different traditions of remembrance, bear out Hartman's insistence on the transcultural circulation of the memory of the disaster as well as on the vital role of concrete experience, they at the same time manage to throw into stark relief one crucial limitation of Hartman's work. For Hartman, the crystallization of memory can never materialize as a collective effort, as that would, for him, imply an identitarian claim on what video testimony renders 'un-claimable'; the site of crystallization - where the transcultural nature of memory is realized - can, for Hartman, only ever be the individual (rather than the collective) subject experiencing its non-experience of the disaster. ${ }^{44}$ The only sense of collectivity that this picture allows is what Alphonso Lingis once called a community of those who have nothing in common. ${ }^{45}$ Such an insistence on an exceedingly bare form of togetherness precludes what for Rothberg is one of the main motivations for retrieving the multidirectional constitution of collective memory: the fact that it makes room for "complex acts of solidarity in which historical memory serves as a medium for the creation of new communal and political identities. ${ }^{" 46}$ What Hartman's work fails to recognize is that in transcultural contexts, some sort of collective memory claim may well be strategically necessary in order to promote such solidarity.

Still, in spite of this limitation, Hartman's insistence on the careful 'un-claiming' of trauma in its turn offers one crucial addition to Rothberg's theory of the multidirectionality of memory - of memory “as subject to ongoing negotiation, cross-referencing, and borrowing; as productive and not privative. ${ }^{, 47}$ Rothberg insists on "the productive, intercultural dynamic of multidirectional memory" in order to dislodge the idea that collective identity is predicated on exclusive memory claims. He rejects the closely connected ideas "that a straight line runs from memory to identity and that the only kinds of memories and identities that are therefore possible are ones that exclude elements of alterity and forms of commonality with others."48 
Rothberg codes the distinction between a productive interaction of memories and exclusionary claims on particular memories that aggressively resist such interaction as the difference between multidirectional and competitive memory. I argue that we can arrive at a better - and certainly a more realistic - phenomenology of such a destructive relationship between memory, identity, and violence that refuses interaction by mapping it onto Freud's seminal account of melancholia - which implicitly structures Hartman's work on the circulation of memories. As is well known, Freud's seminal essay on "Trauer und Melancholia" ["Mourning and Melancholia"] opposes two ways of dealing with loss: mourning, which Freud considers a normal, healthy response to loss, and melancholia, which he castigates as a pathological and self-destructive response. In normal processes of mourning, the mourner is able to work through grief in a relatively unambivalent fashion; she slowly and painfully reconnects to the outside world as she regains access to the energies that had been invested in the object that is now lost. The melancholic, in contrast, is unable to enter into a dynamic relation with new love objects, and even with the outside world more generally, as she fails to detach her energies from the object she has lost. ${ }^{49}$ In melancholia, experiences of suffering are not shared or circulated, but rather shielded away from the outside world. Melancholia is accompanied by feelings of "self-loathing" and a "numbed disconnection" from other people and the world; failing to bring the precise extent and nature of the loss suffered to consciousness, it is a form of grieving that is "blocked by unconscious and displaced aggression." ${ }^{, 50}$ Because of this blockage, it forbids the renewal of dynamic object-relations, and forecloses "the capacity to experience new people and relations with spontaneity, with a receptivity to experience, to newness, to changes in oneself and others"a capacity that requires a minimal willingness to mourn. ${ }^{51}$ Melancholia, in other words, appears as a pathology that checks the productive, interpersonal, and intercultural circulation 
of memories of suffering and loss and that predicates personal and collective identity on an uncompromising attachment to, and an exclusionary claim of, particular traumas or losses.

Such a melancholic conception of identity, which, in Rothberg's words, assumes "that a direct line runs between remembrance of the past and the formation of identity in the present, ${ }^{, 52}$ is widespread in contemporary culture. Roger Luckhurst has noted that, in our memory culture, collective identities tend to "unite around the re-experiencing of their woundedness," rather than recognize their implication in the memories of others. ${ }^{53}$ The account of melancholia suggests that the refusal of multidirectionality that Rothberg identifies as the model of competitive memory is a species of melancholia. Indeed, melancholia is the real enemy of multidirectional memory: not only does it rob the subject of any desire to implicate itself in the world and in other lives, the feelings of self-beratement it generates also, as Rothberg notes in relation to the very comparable notion of 'victimization,' "erode[s] the bases of selfhood necessary for relationship with others." ${ }^{, 54}$ If we accept the prevalence of melancholic notions of collective identity in our memory culture, Hartman's insistence on the 'un-claiming' of memory, which liberates memories from such exclusionary identity-claims, emerges as a viable strategy for the promotion of multidirectionality. Moreover, the concept of melancholia allows another virtue of Hartman's account to stand out: his theorization of the phantomization and derealization that are spread by the visual media helps to explain why certain groups are panicked into the compensatory affirmation of an identitarian purity that is untainted by ghostliness and otherness. ${ }^{55}$

Hartman's case for the 'un-claiming' of trauma is more attentive to the threats of melancholia than Rothberg's account. One of Rothberg's strategies to theorize multidirectional memory is through a novel reading of Freudian screen memory. For Rothberg, screen memory does not promote a competitive notion of memory, as "the displacement that takes place in screen memory ... functions as much to open up lines of 
communication with the past as to close them off." He duly notes that "[i]n contemporary societies, mediascapes of all kinds play a predominant role" in opening up these lines, but he does not consider the circulation of multiple memories as a problem - indeed, if anything, it supports his case for multidirectional memory's capacity to juxtapose "two or more disturbing memories and disrupt[] everyday settings. ${ }^{, 56}$ What is missing in this account is the realization that such everyday settings may already be saturated by "the proliferation and dailiness of second-order images of trauma" through the media, and that the attempt to disrupt the everyday through ever new memory claims may only end up hastening a melancholic refusal of multidirectionality. ${ }^{57}$ Hartman's account of the dynamic of derealization and melancholia makes it possible to see that Rothberg's case for multidirectionality's capacity to "construct solidarity out of specificities, overlaps, and echoes of different historical experiences" threatens to pre-empt itself, as it unwittingly induces the melancholic closure of competitive memory it aims to displace. ${ }^{58}$ For Rothberg, competitive memory is merely a rival model for the understanding of the dynamics of collective memory; what Hartman adds to this account is that it is also a melancholic pathology that cannot simply be dislodged by comparative thinking alone.

IV

For Alexander, the circulation of the Holocaust beyond the confines of Jewish experience in the last half century has required "detaching the issues surrounding the systematic exercise of violence against ethnic groups from any particular ethnicity, religion, nationality, time, or place." This outright de-particularization of trauma has made possible a process of "deepening emotional identification." ${ }^{, 59}$ In his response to Alexander, Rothberg notes that detachment alone is never enough: memories have to be "'reattached' to a new context in order to have any moral purchase." 60 The peculiarity of Hartman's insistence on the 'un-claiming' of 
trauma is that, while it recognizes this need for reattachment - through its uncompromising insistence on concrete, individual experience - it paradoxically proposes an attachment to the fact of our fateful detachment from the disaster. The very process of reattachment, in other words, precludes the mobilization of memory for forging new collectivities.

We can rephrase this singular position in terms of the familiar trope of the so-called "sacralization" of the Holocaust. Hartman's repeated insistence on the reality of "thousands of survivor testimonies that actually exist" testifies to his refusal to surrender the memory of the Holocaust to such categories as the unrepresentable, the incomprehensible, or the ineffable; ${ }^{61}$ the fact that the Holocaust is structurally articulated with the trauma of industrialization and with images of contemporary terror in Hartman's work, moreover, undoes the sacred position of inviolable uniqueness. Still, such a desacralization of the Holocaust does not for all that amount to an outright profanation of it: Hartman's theorization of the genre of video testimony betrays a desire to replace such a sacred unavailability with a hardly less forbidding awareness of the Holocaust's withdrawal from our claims upon it. If we understand profanation as a process in which "that which was unavailable and separate loses its aura and is returned to use," then Hartman's desacralization of the Holocaust at the same time paradoxically amounts to its 'deprofanation. ${ }^{, 62}$ Hartman recognizes the articulation of the Holocaust with other disasters and its implication in the experience of different histories and identities, yet these differences are not allowed to matter. The memories of disaster circulate in a limbo that precludes both their sacralization and their mobilization for forging strategic alliances that hold the potential to further justice and solidarity.

Hartman's relocation of trauma - beyond both separation and claiming - while being decidedly unhelpful for forging a progressive politics, offers an entirely realistic account of the circulation of memories of disaster and images of suffering in contemporary media culture. Indeed, while many members of metropolitan audiences have not themselves 
experienced extreme violence, they manifestly live in a media-saturated culture in which traces of suffering circulate promiscuously. In such a culture, direct traumatic experiences (and the possibilities to capitalize on them) are less readily available than the refracted images of the suffering of others. Here video testimony intervenes to mediate the contemporary subject's relation to past disasters and contemporary terror from which it is inevitably removed yet by which it is unavoidably addressed. Hartman theorizes video testimony as a technology that can prevent the fateful collapse of the ghostliness and intangibility of traumatic memory into melancholic claims of exclusiveness and competition.

Still, while Hartman's warnings against a melancholic censoring of the circulation of memory touches on a crucial dimension of the way collective memory actually functions in Western media culture, it fails to imagine situations in which strategic claims of identity and memory can play a vital role in promoting justice. It is here that Hartman's work, in spite of its recognition of the interconnectedness of memories and of the untenability of exclusive and exclusionary claims upon them, appears to be not nearly transcultural enough. For nondominant groups, the melancholic refusal to surrender particular memories and to let go of particular losses can sustain claims for recognition and justice that can, in their turn, be part of the same dialogic and multidirectional process in which the interrelatedness of memory is confirmed. Indeed, if the sheer multiplicity of memory claims is likely to incite a melancholic overreaction, then so is an outright refusal to recognize such claims - which is the sad fate of many minoritarian bids for acknowledgement. Hartman's account of the collective memory of extreme violence shares this blindness with his account of modernity, in which the idiosyncratic identification of English culture with the fantasy of an unhindered and untraumatic national continuity fails to recognize the fact that England has not ceased to export violence and suffering in the name of imperialism and colonialism, or, more recently, a war on terror. England's spectacular avoidance of national trauma coincided with the massive 
exportation of trauma. His account of modernity is, in other words, undergirded by a foreclosure of Western modernity's colonial realities. This foreclosure asserts itself in his work on the memory of extreme violence as a failure to imagine that melancholic claims of memory and identity can in certain circumstances be something else than a repetition of the disaster they recall.

${ }^{1}$ Cathy Caruth, “Trauma and Experience: Introduction”, in Trauma: Explorations in Memory, ed. Cathy Caruth (Baltimore: Johns Hopkins University Press, 1995), 3-12, 11.

${ }^{2}$ See Stef Craps and Gert Buelens, "Introduction: Postcolonial Trauma Novels," Studies in the Novel 40 (2008), 1-12, 1-4.

${ }^{3}$ Bryan Cheyette, "Venetian Spaces: Old-New Literatures and the Ambivalent Uses of Jewish History," in Reading the "New" Literatures in a Post-Colonial Era, ed. Susheila Nasta (Cambridge: Boydell and Brewer, 2000), 53-72, 54.

${ }^{4}$ For Hartman, see especially Geoffrey Hartman, “On Traumatic Knowledge and Literary Studies," New Literary History 26 (1995), 537-63. For Laub, see Shoshana Felman and Dori Laub, Testimony: Crises of Witnessing in Literature, Psychoanalysis, and History (New York: Routledge, 1992).

${ }^{5}$ Geoffrey Hartman, The Unmediated Vision: An Interpretation of Wordsworth, Hopkins, Rilke, and Valéry (New Haven: Yale University Press, 1954); Geoffrey Hartman, Wordsworth's Poetry 1787-1814 (New Haven: Yale University Press, 1964).

${ }^{6}$ Geoffrey Hartman, The Fateful Question of Culture (New York: Columbia University Press, 1997), 7.

${ }^{7}$ Hartman, The Fateful Question, 7.

${ }^{8}$ Hartman, The Fateful Question, 21, 73.

${ }^{9}$ Hartman, The Fateful Question, 27. 
${ }^{10}$ Ian Balfour and Rebecca Comay, "The Ethics of Witness: An Interview with Geoffrey Hartman," in Lost in the Archives, ed. Rebecca Comay (Toronto: Alphabet City Media, 2002), 492-509, 494, 497; Geoffrey Hartman, Easy Pieces (New York: Columbia University Press, 1985), 175.

${ }^{11}$ Geoffrey Hartman, "Memory.com: Tele-Suffering and Testimony in the Dot Com Era," $\underline{\text { Raritan }} 19$ (2000), 1-18, 1-5.

${ }^{12}$ Hartman, The Fateful Question, 73.

${ }^{13}$ Hartman coins the term "optic" in an interview with Ian Balfour and Rebecca Comay. He at the same time refuses to call this "optic" an "aesthetic," most likely in order to distinguish it from what the interviewers had just refered to as "the Spielberg Aesthetic" and "the Riefenstahl aesthetic." Ian Balfour and Rebecca Comay, "The Ethics of Witness," 494-95. ${ }^{14}$ Hartman, "Memory.com," 9.

${ }^{15}$ Hartman's turn to the memory of the Holocaust in the early 1980s also confirms standard accounts of the emergence of the Holocaust in American life. See especially Peter Novick, The Holocaust in American Life (Boston: Houghton Mifflin, 1999).

${ }^{16}$ Geoffrey Hartman, “Shoah and Intellectual Witness;” Partisan Review 65 (1998), 37-48, $39-40$.

${ }^{17}$ Balfour and Comay, "The Ethics of Witness," 494.

${ }^{18}$ Balfour and Comay, "The Ethics of Witness," 496.

${ }^{19}$ Geoffrey Hartman, “The Humanities of Testimony: An Introduction,” Poetics Today 27 (2006), 249-60, 252; Jennifer Ballengee, "Witnessing Video Testimony: An Interview with Geoffrey Hartman,” Yale Journal of Criticism 14 (2001), 217-32, 223.

${ }^{20}$ Hartman, "The Humanities of Testimony,” 260.

${ }^{21}$ Hartman, "Shoah and Intellectual Witness," 39.

${ }^{22}$ Hartman, "Shoah and Intellectual Witness," 39. 
${ }^{23}$ Hartman, The Fateful Question, 130n12.

${ }^{24}$ Hartman, "Memory.com," 10.

${ }^{25}$ Balfour and Comay, "The Ethics of Witness," 501.

${ }^{26}$ Hartman, "The Humanities of Testimony," 254.

${ }^{27}$ Hartman, "Memory.com," 4.

${ }^{28}$ Geoffrey Hartman, The Longest Shadow: In the Aftermath of the Holocaust (Bloomington: Indiana University Press, 1996), 83.

${ }^{29}$ Hartman, The Longest Shadow, 83-88. For a good discussion of Hartman's argument against Spielberg, see Frances Ferguson, “Romantic Memory,” Studies in Romanticism 35 (1996), 509-33, 516-23.

${ }^{30}$ Hartman, "The Humanities of Testimony," 257.

${ }^{31}$ Hartman, The Longest Shadow, 44, 86.

${ }^{32}$ Geoffrey Hartman, Easy Pieces (New York: Columbia University Press, 1985), 99.

Interestingly, Hartman analyzes the case of Benjamin Wilkomirski in these terms: faced with "the pressure to own a distinct identity," Wilkomirski, through his exposure to the images and stories of the camp, "internalizes what he has heard and read, and it emerges as his own experience." Hartman sees this case of "memory-envy" as a direct consequence of the broad circulation of accounts, memoirs, and images of suffering. See Hartman, "Memory.com," 1314.

${ }^{33}$ Hartman, The Fateful Question, 130n12.

${ }^{34}$ Marianne Hirsch, "Surviving Images: Holocaust Photographs and the Work of Postmemory," The Yale Journal of Criticism 14 (2001), 5-37, 8.

${ }^{35}$ Ernst van Alphen, "Second-Generation Testimony, Transmission of Trauma, and Postmemory," Poetics Today 27 (2006), 473-88, 477.

${ }^{36}$ Hartman, The Longest Shadow, 155. 
${ }^{37}$ Hartman, "Memory.com," 12.

${ }^{38}$ Marianne Hirsch, “The Generation of Postmemory,” Poetics Today 29 (2008), 103-28, 110.

${ }^{39}$ Philippe Lacoue-Labarthe and Jean-Luc Nancy, “The Nazi Myth,” Critical Inquiry 16 (1990), 291-312, 299.

${ }^{40}$ Jeffrey Alexander a.o., Remembering the Holocaust: A Debate (Oxford: Oxford University Press, 2009), 3.

${ }^{41}$ Alexander, Remembering the Holocaust, 37.

${ }^{42}$ Michael Rothberg, Multidirectional Memory: Holocaust Memory in the Age of Decolonization (Stanford: Stanford University Press, 2009), 264. For Rothberg's extensive critique of Alexander, see Rothberg, Multidirectional Memory, 263-66, and Michael Rothberg, "Multidirectional Memory and the Universalization of the Holocaust," in Jeffrey Alexander a.o., Remembering the Holocaust, 123-34.

${ }^{43}$ Rothberg, Multidirectional Memory, 80.

${ }^{44}$ As the operation of video testimony is modeled on that of Wordsworth's poetry, this emphasis on the individual subject is a reminder that Hartman's claim on Wordsworth never fills in how Wordsworth's poetry managed to affect the national imagination, other than through the accumulative effects of individual reading practices.

${ }^{45}$ Alphonso Lingis, The Community of Those Who Have Nothing in Common (Bloomington: Indiana University Press, 1994).

${ }^{46}$ Rothberg, Multidirectional Memory, 11.

${ }^{47}$ Rothberg, Multidirectional Memory, 3.

${ }^{48}$ Rothberg, Multidirectional Memory, 3-4.

${ }^{49}$ Sigmund Freud, "Trauer und Melancholie," in Studienausgabe III, ed. Alexander Mitscherlich a.o. (Frankfurt/Main: Suhrkamp, 1975), 193-213. 
${ }^{50}$ Greg Forter, “Against Melancholia: Contemporary Mourning Theory, Fitzgerald's The Great Gatsby, and the Politics of Unfinished Grief,” Differences 14 (2003), 134-70, 139; Seth Moglen, “On Mourning Social Injury,” Psychoanalysis, Culture \& Society 10 (2005), $151-67,159$.

${ }^{51}$ Moglen, “On Mourning Social Injury,” 162. Moglen’s work makes clear that such a willingness to mourn need not entail a full-scale return to a Freudian notion of restitutive mourning. In the field of critical theory, the critique of the disciplinary demands for normalization implied by such a notion of restitutive mourning has led to a revalorization of melancholia as a heroic refusal to surrender a lost object to a public space that dishonors its memory, rather than a pathological inability to let go of a lost object. The articles by Moglen and Forter (see previous note) offer arguments why melancholia is not a sustainable critical stance; among others, they note that the 'depathologization' or 'naturalization' of melancholia forgets melancholia's profound affective ambivalence - the fact that it is characterized "by numbed disconnection and a self-loathing whose logical conclusion is suicide." See Forter, “Against Melancholia," 139. Their critique of melancholia informs my decision to use the category in order to describe a number of problems besetting the transcultural circulation of memory.

${ }^{52}$ Rothberg, Multidirectional Memory, 3.

${ }^{53}$ Roger Luckhurst, The Trauma Question (Abingdon: Routledge, 2008), 2.

${ }^{54}$ Rothberg, Multidirectional Memory, 163.

${ }^{55}$ For an account of Freudian melancholia as a stabilization strategy that invokes the phantasm of loss even if no identifiable loss has occurred, see Giorgio Agamben, Stanzas: Word and Phantasm in Western Culture (Minneapolis: University of Minnesota Press, 1993), 19-21. For the resonances of this strategy in postwar criticism, see Pieter Vermeulen, 
“Greenblatt's Melancholy Fetish: Literary Criticism and the Desire for Loss,” Textual Practice 24 (2010), 483-500.

${ }^{56}$ Rothberg, Multidirectional Memory, 12-16.

${ }^{57}$ Hartman, The Fateful Question, 130n12.

${ }^{58}$ Rothberg, Multidirectional Memory, 16 . The variety of cases Rothberg deals with makes it impossible to identify his theory of memory with a particular aesthetic; still, his descriptions of the ways in which literary, artistic, and journalistic work has served as a vehicle and catalyst for multidirectional memory often draws upon the notion of "juxtaposition," a term which indicates the underdetermined articulation of different memories and histories staged in these works. For Hartman, such juxtapositions, in their dependence on an experience of shock and defamiliarization, inevitably court the risk of retraumatization. This also explains Hartman's preference for video over photography, a medium which, for him, has a greater potential for retraumatization. See Balfour and Comay, "The Ethics of Witness," 494; Geoffrey Hartman, “The Struggle against the Inauthentic: An Interview by Nicholas Chare,” Parallax 10 (2004), 72-77, 77; Cathy Caruth, “An Interview with Geoffrey Hartman,” Studies in Romanticism 35 (1996), 630-51, 643.

${ }^{59}$ Alexander, Remembering the Holocaust, 49.

${ }^{60}$ Rothberg, "Multidirectional Memory and the Universalization of the Holocaust," 128.

${ }^{61}$ Geoffrey Hartman, Scars of the Spirit: The Struggle Against Inuathenticity (New York: Palgrave Macmillan, 2002), 90.

${ }^{62}$ The definition of profanation is Giorgio Agamben's. See Giorgio Agamben, Profanations (New York: Zone Books, 2007), 77. 